\title{
PENGARUH KONSENTRASI DAN INTERVAL PEMUPUKAN NPK TERHADAP PERTUMBUHAN MARIGOLD (Tagetes erecta L.)
}

\section{Effect of NPK Concentration and Application Interval on Growth of Marigold (Tagetes erecta $\mathbf{L}$.)}

\section{E. Dwi Sulistya Nugroho ${ }^{1}$, Ardian Elonard ${ }^{1 *}$, Rusmana ${ }^{2}$, dan Sri Ritawati ${ }^{2}$}

\author{
1) Balai Penelitian Tanaman Hias, \\ Jl. Raya Ciherang, Segunung, Pacet, Cianjur, Jawa Barat \\ ${ }^{2)}$ Universitas Sultan Ageng Tirtayasa, \\ Jalan Raya Jakarta Km 4, Panancangan, Kota Serang, Banten, Jawa Barat
}

*Alamat Korespondensi: elonard.4rdian@gmail.com

\begin{abstract}
ABSTRAK
Marigold merupakan tanaman herba hias yang saat ini mulai menjadi primadona serta memiliki nilai ekonomis yang cukup tinggi. Oleh karena itu, produktivitas dan kualitas bunga marigold perlu ditingkatkan. Cara pemberian serta jenis pupuk yang tepat menjadi salah satu hal yang perlu diperhatikan agar menjadi efektif terhadap tanaman marigold. Tujuan dari penelitian ini adalah untuk mengetahui keefektifan penggunaan pupuk NPK dengan konsentrasi dan interval pemupukan terhadap pertumbuhan tanaman marigold. Penelitian didesain dengan Rancangan Acak Kelompok (RAK) yang terdiri dari dua faktor. Faktor pertama merupakan konsentrasi pupuk NPK yang terdiri dari tiga taraf, yaitu tanpa aplikasi pupuk, $100 \mathrm{mg} / \mathrm{liter}$ air, dan $150 \mathrm{mg} / \mathrm{liter}$ air. Faktor kedua adalah interval pemupukan NPK yang terdiri dari 3 taraf, yaitu 1 kali/minggu, $1 \mathrm{kali} / 2$ minggu, dan $1 \mathrm{kali} / 3$ minggu. Seluruh perlakuan diulang sebanyak 3 kali, sehingga didapatkan kombinasi perlakuan sebanyak 27 plot. Parameter pengamatan meliputi tinggi tanaman, jumlah daun, diameter batang, inisiasi bunga, diameter bunga, lama kesegaran bunga. Perlakuan konsentrasi $150 \mathrm{mg} /$ liter air dengan interval pemupukan $1 \mathrm{kali} / \mathrm{minggu}$ menjadi input yang optimal untuk pertumbuhan tanaman marigold.
\end{abstract}

Kata kunci: marigold, konsentrasi, interval, pupuk NPK

\begin{abstract}
Marigolds are well known as ornamental herbaceous plants and have high economic value. Therefore, the productivity and quality of marigold flowers needs to be improved. Application technique and proper type of fertilizer is one thing that needs to be considered in order to be effective. The purpose of this research was to determine the effectiveness of NPK fertilizers concentration and application intervals on growth of marigold. This research was designed with a Randomized Complete Block Design (RCBD) consisting of two factors. The first factor was concentration of NPK fertilizer which consists of three levels i.e. without fertilizer, $100 \mathrm{mg} /$ liter of water, and $150 \mathrm{mg} /$ liter of water. The second factor was the NPK fertilizer application interval which consists of 3 levels, i.e. 1 time/week, 1 time/2 weeks, and 1 time/3 weeks. All treatments were repeated 3 times, so the combination of 27 plots was obtained. Observation parameters were plant height, number of leaves, stem diameter, flower initiation, flower diameter, flower freshness duration. The concentration of $150 \mathrm{mg} /$ liter of water with a fertilizer interval of 1 time/week was an optimal input for the growth of marigold.
\end{abstract}

Keywords: marigold, concentration, interval, NPK fertilizer

\section{PENDAHULUAN}

Marigold merupakan tanaman herba hias yang biasa digunakan sebagai tanaman pembatas atau tanaman pagar pada budidaya tanaman. Perannya sebagai tanaman pembatas tidak serta merta membatasi tanaman ini hanya digunakan sebagai tanaman penyela saja. Tanaman ini ternyata memiliki banyak peran dalam berbagai bidang, beberapa diantaranya adalah sebagai obat, pewarna, pakan ternak dan juga unggas. Tanaman ini memiliki 
banyak kandungan zat yang dapat digunakan dan dimanfaatkan sebagai antioksidan alami, antibakteria, antinematoda, dan antimikrobia. Menurut Ariana et al. (2011), kandungan karotenoid pada marigold mencapai $680 \mathrm{mg} / \mathrm{kg}$ dan xantofil 56,32 mg/kg serta mengandung zat lain yaitu flavonoid dan polifenol.

Mengacu pada hal tersebut dapat dilihat bahwa kebutuhan bunga marigold cukup tinggi serta memiliki nilai ekonomis yang tinggi, maka produktivitas dan kualitas bunga marigold perlu ditingkatkan. Salah satu hal yang perlu diperhatikan dalam usaha peningkatan produktivitas dan kualitas bunga adalah faktor pemupukan. Menurut Susilo et al. (2010), pemupukan merupakan hal penting yang perlu dilakukan untuk menyediakan unsur hara bagi tanaman, karena kandungan unsur hara dalam tanah bervariasi dan berubah-ubah akibat kehilangan unsur hara melalui pencucian maupun penguapan, sehingga melalui pemupukan yang diberikan unsur hara tetap tersedia dan terlebih dapat meningkatkan produktivitas dan mutu tanah (Nath, 2013).

Salah satu pupuk yang praktis dan sering digunakan dalam budidaya tanaman adalah pupuk NPK, dimana pupuk ini mengandung beberapa unsur hara sekaligus yang dibutuhkan oleh tanaman, sehingga biasa disebut dengan pupuk majemuk. Menurut Puspita et al. (2017), penggunaan pupuk NPK dengan dosis $20 \mathrm{~g} /$ tanaman dapat memberikan hasil yang baik terhadap waktu munculnya kuncup bunga, mekar bunga, diameter tangkai bunga, serta jumlah kuntum bunga sedap malam. Hal tersebut menunjukkan bahwa tanaman sangat responsif terhadap pemberian pupuk NPK, baik dari segi pertumbuhan vegetatif maupun generatif, sehingga penggunaan pupuk ini dapat direkomendasikan pada tanaman marigold dalam meningkatkan pertumbuhan dan produktivitas.

Hal penting yang perlu diperhatikan dalam penggunaan pupuk NPK salah satunya adalah tingkat kehilangan akibat penguapan, dimana pupuk ini biasa diberikan pada tanaman dengan cara disebar. Berdasarkan hal tersebut maka perlu cara untuk menekan tingkat penguapan pupuk NPK yang diberikan, sehingga dapat lebih efektif terhadap tanaman. Sistem pemupukan kocor menjadi alternatif yang dapat digunakan untuk meningkatkan serapan hara oleh tanaman. Sesuai dengan penelitian Ebrahim (2012), yang menyatakan bahwa pupuk Kalium dengan konsentrasi $0,3 \mathrm{~g} / 1$ yang diberikan dengan sistem kocor dapat meningkatkan panjang akar, bobot basah dan kering akar, serta hasil tanaman strawberry. Mengacu hasil penelitian tersebut maka penerapan sistem kocor juga dapat diaplikasikan pada tanaman hias dalam kaitannya untuk 
meningkatkan pertumbuhan dan produktivitas marigold.

Pemupukan melalui sistem tersebut dinilai lebih efektif dan efisien dalam penyediaan unsur hara dalam tanah yang dibutuhkan oleh tanaman. Hal yang perlu dicermati dari sistem ini adalah penggunaan konsentrasi yang optimal untuk tanaman marigold, sehingga pertumbuhan dan produktivitasnya dapat meningkat. Andriolo et al. (2011), menyebutkan bahwa peningkatan konsentrasi $\mathrm{N}$ dalam larutan nutrisi justru menyebabkan penurunan jumlah daun, jumlah tunas, dan berat kering akar tanaman strawberry. Berdasarkan hal tersebut maka konsentrasi yang tepat menjadi salah satu kunci yang perlu diperhatikan dalam usaha budidaya tanaman, khususnya marigold. Sinergis dengan hal tersebut, frekuensi pupuk yang diberikan juga menjadi bagian penting dalam suatu teknologi pemupukan. Menurut Bastari (2006), menyatakan bahwa faktor frekuensi pemupukan, cara pemberian, serta bentuk pupuk yang digunakan secara tepat merupakan faktor penting dalam upaya untuk menjaga ketersediaan hara dalam tanah, sehingga perlu dikaji mengenai penentuan konsentrasi dan frekuensi pemupukan yang tepat pada tanaman marigold guna meningkatkan pertumbuhan dan produktivitasnya.

\section{METODE PENELITIAN}

Penelitian dilaksanakan pada tahun 2019 di Kebun Percobaan Balai Penelitian Tanaman Hias, Segunung, Cianjur. Peralatan yang digunakan dalam penelitian ini antara lain cangkul, sekop, handsprayer, alat tulis, jangka sorong, pengaris, dan pot, sedangkan bahan yang digunakan antara lain benih marigold, pupuk NPK, pestisida, limbah baglog jamur. Penelitian didesain dengan Rancangan Acak Kelompok (RAK) yang terdiri dari dua faktor. Faktor pertama adalah konsentrasi pupuk NPK yang terdiri dari tiga taraf, yaitu tanpa aplikasi pupuk, $100 \mathrm{mg} /$ liter air, dan $150 \mathrm{mg} /$ liter air. Faktor kedua adalah interval pemupukan yang terdiri dari tiga taraf, yaitu 1 kali/minggu, 1 kali/2 minggu, dan 1 kali/3 minggu. Seluruh perlakuan diulang sebanyak 3 kali, sehingga didapatkan kombinasi percobaan sebanyak 27 plot. Parameter yang diamati meliputi tinggi tanaman, jumlah daun, diameter batang, inisiasi bunga, diameter bunga, dan lama kesegaran bunga.

Data hasil penelitian dianalisis dengan menggunakan sidik ragam dengan taraf $p=0,05$ dan diuji lanjut dengan menggunakan Uji Jarak Berganda Duncan (DMRT) dengan taraf $p=0,05$, apabila terdapat perbedaan yang nyata antar perlakuan. 


\section{HASIL DAN PEMBAHASAN}

\section{Hasil}

Terdapat perbedaan yang nyata pada perlakuan konsentrasi NPK terhadap rerata tinggi tanaman pada umur 6 MST, 8 MST, dan 10 MST, sedangkan pada perlakuan interval pemupukan NPK menunjukkan bahwa terdapat perbedaan yang nyata terhadap tinggi tanaman pada umur $4 \mathrm{MST}$, 6 MST, 8 MST, dan 10 MST.

Perlakuan konsentrasi $150 \mathrm{mg} /$ liter air dengan interval pemupukan $1 \mathrm{kali} /$ minggu menunjukkan tinggi tanaman yang tertinggi. Hal ini diduga bahwa konsentrasi pupuk NPK $150 \mathrm{mg} /$ liter air dengan interval penyiraman $1 \mathrm{kali} /$ minggu merupakan perlakuan yang optimal, sehingga berpengaruh terhadap tinggi tanaman marigold.

Hasil sidik ragam pada Tabel 2. menunjukkan bahwa terdapat perbedaan yang nyata pada perlakuan konsentrasi NPK terhadap rerata jumlah daun pada umur 2 MST dan 10 MST, sedangkan pada perlakuan interval pemupukan NPK menunjukkan bahwa terdapat perbedaan

Tabel 1. Tinggi tanaman $(\mathrm{cm})$ marigold pada konsetrasi dan interval pemupukan NPK berbeda

\begin{tabular}{lcrrrc}
\hline \multirow{2}{*}{ Perlakuan } & \multicolumn{5}{c}{ Umur tanaman } \\
\cline { 2 - 6 } & $2 \mathrm{MST}$ & $4 \mathrm{MST}$ & $6 \mathrm{MST}$ & $8 \mathrm{MST}$ & $10 \mathrm{MST}$ \\
\hline Konsentrasi NPK & $7,29 \mathrm{a}$ & $8,38 \mathrm{a}$ & $9,71 \mathrm{~b}$ & $11,66 \mathrm{~b}$ & $13,82 \mathrm{c}$ \\
Tanpa aplikasi & $7,26 \mathrm{a}$ & $8,55 \mathrm{a}$ & $10,02 \mathrm{~b}$ & $12,25 \mathrm{~b}$ & $15,12 \mathrm{~b}$ \\
$100 \mathrm{mg} /$ liter air & $7,51 \mathrm{a}$ & $8,82 \mathrm{a}$ & $10,57 \mathrm{a}$ & $13,04 \mathrm{a}$ & $16,54 \mathrm{a}$ \\
$150 \mathrm{mg} /$ liter air & & & & & \\
\hline Interval Pemupukan NPK & $7,53 \mathrm{a}$ & $9,04 \mathrm{a}$ & $10,81 \mathrm{a}$ & $13,28 \mathrm{a}$ & $16,44 \mathrm{a}$ \\
$1 \mathrm{kali} /$ minggu & $7,24 \mathrm{a}$ & $8,37 \mathrm{~b}$ & $9,90 \mathrm{~b}$ & $11,94 \mathrm{~b}$ & $14,50 \mathrm{~b}$ \\
$1 \mathrm{kali} / 2$ minggu & $7,29 \mathrm{a}$ & $8,34 \mathrm{~b}$ & $9,59 \mathrm{~b}$ & $11,73 \mathrm{~b}$ & $14,55 \mathrm{~b}$ \\
1 kali/3 minggu & 4,10 & 4,92 & 5,28 & 5,94 & 7,39 \\
\hline Koefisien Keragaman $(\%)$ & &
\end{tabular}

Keterangan: Nilai yang diikuti huruf yang sama pada kolom yang sama menunjukkan tidak berbeda nyata menurut Uji Jarak Berganda Duncan pada taraf kepercayaan 95 \%.

Tabel 2. Jumlah daun tanaman marigold pada konsetrasi dan interval pemupukan NPK berbeda

\begin{tabular}{llllll}
\hline \multirow{2}{*}{ Perlakuan } & \multicolumn{5}{c}{ Umur tanaman } \\
\cline { 2 - 6 } & $2 \mathrm{MST}$ & $4 \mathrm{MST}$ & $6 \mathrm{MST}$ & $8 \mathrm{MST}$ & $10 \mathrm{MST}$ \\
\hline Konsentrasi NPK & & & & & \\
Tanpa aplikasi & $5,67 \mathrm{a}$ & $7,81 \mathrm{a}$ & $6,85 \mathrm{a}$ & $7,63 \mathrm{a}$ & $9,15 \mathrm{c}$ \\
$100 \mathrm{mg} /$ liter air & $5,36 \mathrm{~b}$ & $7,96 \mathrm{a}$ & $7,70 \mathrm{a}$ & $8,26 \mathrm{a}$ & $9,85 \mathrm{~b}$ \\
$150 \mathrm{mg} /$ liter air & $5,65 \mathrm{ab}$ & $8,11 \mathrm{a}$ & $7,55 \mathrm{a}$ & $8,45 \mathrm{a}$ & $10,59 \mathrm{a}$ \\
\hline Interval Pemupukan NPK & & & & & \\
$1 \mathrm{kali} /$ minggu & $5,76 \mathrm{a}$ & $8,33 \mathrm{a}$ & $7,74 \mathrm{a}$ & $8,04 \mathrm{a}$ & $10,33 \mathrm{a}$ \\
$1 \mathrm{kali} / 2$ minggu & $5,56 \mathrm{ab}$ & $7,81 \mathrm{~b}$ & $7,30 \mathrm{a}$ & $8,26 \mathrm{a}$ & $9,59 \mathrm{~b}$ \\
1 kali/3 minggu & $5,36 \mathrm{~b}$ & $7,74 \mathrm{~b}$ & $7,07 \mathrm{a}$ & $8,04 \mathrm{a}$ & $9,67 \mathrm{~b}$ \\
\hline Koefisien Keragaman (\%) & 5,35 & 4,01 & 13,74 & 11,31 & 6,31 \\
\hline
\end{tabular}

Keterangan: Nilai yang diikuti huruf yang sama pada kolom yang sama menunjukkan tidak berbeda nyata menurut Uji Jarak Berganda Duncan pada taraf kepercayaan 95. 
Tabel 3. Diameter batang $(\mathrm{mm})$ tanaman marigold pada konsetrasi dan interval pemupukan NPK berbeda

\begin{tabular}{llllll}
\hline \multirow{2}{*}{ Perlakuan } & \multicolumn{5}{c}{ Umur tanaman } \\
\cline { 2 - 6 } & $2 \mathrm{MST}$ & 4 MST & $6 \mathrm{MST}$ & $8 \mathrm{MST}$ & $10 \mathrm{MST}$ \\
\hline Konsentrasi NPK & & & & \\
Tanpa aplikasi & $2,46 \mathrm{a}$ & $2,88 \mathrm{a}$ & $3,44 \mathrm{a}$ & $3,54 \mathrm{a}$ & $3,57 \mathrm{~b}$ \\
$100 \mathrm{mg} /$ liter air & $2,39 \mathrm{a}$ & $2,72 \mathrm{a}$ & $3,47 \mathrm{a}$ & $3,49 \mathrm{a}$ & $3,74 \mathrm{ab}$ \\
$150 \mathrm{mg} /$ liter air & $2,44 \mathrm{a}$ & $2,84 \mathrm{a}$ & $3,55 \mathrm{a}$ & $3,55 \mathrm{a}$ & $3,95 \mathrm{a}$ \\
\hline Interval Pemupukan NPK & & & & \\
$1 \mathrm{kali} /$ minggu & $2,44 \mathrm{a}$ & $2,85 \mathrm{a}$ & $3,50 \mathrm{a}$ & $3,66 \mathrm{a}$ & $3,95 \mathrm{a}$ \\
$1 \mathrm{kali} / 2$ minggu & $2,36 \mathrm{a}$ & $2,78 \mathrm{a}$ & $3,45 \mathrm{a}$ & $3,47 \mathrm{a}$ & $3,67 \mathrm{~b}$ \\
$1 \mathrm{kali} / 3$ minggu & $2,48 \mathrm{a}$ & $2,82 \mathrm{a}$ & $3,51 \mathrm{a}$ & $3,46 \mathrm{a}$ & $3,64 \mathrm{~b}$ \\
\hline Koefisien Keragaman $(\%)$ & 5,35 & 9,91 & 6,21 & 5,71 & 7,01 \\
\hline
\end{tabular}

Keterangan: Nilai yang diikuti huruf yang sama pada kolom yang sama menunjukkan tidak berbeda nyata menurut Uji Jarak Berganda Duncan pada taraf kepercayaan $95 \%$.

Tabel 4. Inisiasi bunga, diameter bunga, dan lama kesegaran bunga tanaman marigold pada konsetrasi dan interval pemupukan NPK berbeda

\begin{tabular}{|c|c|c|c|}
\hline \multirow[b]{2}{*}{ Perlakuan } & \multicolumn{3}{|c|}{ Variabel } \\
\hline & $\begin{array}{l}\text { Inisiasi bunga } \\
\text { (HST) }\end{array}$ & $\begin{array}{l}\text { Diameter bunga } \\
(\mathrm{mm})\end{array}$ & $\begin{array}{c}\text { Lama kesegaran } \\
\text { bunga } \\
\text { (HSP) }\end{array}$ \\
\hline Konsentrasi NPK & hari setelah tanam & $\mathrm{mm}$ & hari setelah panen \\
\hline Tanpa aplikasi & $102,15 \mathrm{a}$ & $41,17 \mathrm{c}$ & $22,22 \mathrm{a}$ \\
\hline $100 \mathrm{mg} /$ liter air & $97,11 \mathrm{~b}$ & $53,99 \mathrm{~b}$ & $20,52 \mathrm{a}$ \\
\hline $150 \mathrm{mg} /$ liter air & $95,26 \mathrm{~b}$ & $58,33 \mathrm{a}$ & $20,11 \mathrm{a}$ \\
\hline \multicolumn{4}{|l|}{ Interval Pemupukan NPK } \\
\hline $1 \mathrm{kali} / \mathrm{minggu}$ & $93,00 \mathrm{c}$ & $56,53 \mathrm{a}$ & $19,19 \mathrm{a}$ \\
\hline $1 \mathrm{kali} / 2 \mathrm{minggu}$ & $99,59 \mathrm{ab}$ & $49,61 \mathrm{~b}$ & $22,70 \mathrm{a}$ \\
\hline $1 \mathrm{kali} / 3 \mathrm{minggu}$ & $101,93 \mathrm{a}$ & $47,36 \mathrm{~b}$ & $20,96 \mathrm{a}$ \\
\hline Koefisien Keragaman (\%) & 3,46 & 5,87 & 14,20 \\
\hline
\end{tabular}

Keterangan: Nilai yang diikuti huruf yang sama pada kolom yang sama menunjukkan tidak berbeda nyata menurut Uji Jarak Berganda Duncan pada taraf kepercayaan 95 \%.

yang nyata terhadap rerata jumlah daun pada umur $2 \mathrm{MST}$, $4 \mathrm{MST}$, dan $10 \mathrm{MST}$.

Terdapat perbedaan yang nyata pada perlakuan konsentrasi NPK terhadap diameter batang umur $10 \mathrm{MST}$, begitu juga pada perlakuan interval pemupukan, Interaksi antara perlakuan konsentrasi pupuk dan interval pemupukan berpengaruh nyata pada diameter batang umur 4 MST dan 6 MST.

Ada perbedaan yang nyata pada perlakuan konsentrasi NPK terhadap inisiasi bunga dan diameter batang, begitu juga dengan perlakuan interval pemupukan, Perlakuan dengan pupuk NPK menunjukkan inisiasi pembungaan yang lebih cepat dibandingkan dengan tanpa 
pemupukan NPK, sedangkan pada parameter diameter bunga perlakuan konsentrasi NPK $150 \quad \mathrm{mg} /$ liter air menunjukkan diameter bunga tertinggi. Pada perlakuan interval pemupukan NPK 1 kali/minggu menunjukkan inisiasi pembungaan yang tercepat dan diameter bunga tertinggi.

\section{Pembahasan}

Tinggi tanaman dan diameter batang menunjukan hasil yang selaras dari perlakuan pupuk NPK pada fase pertumbuhan vegetatif lanjut. Hal ini diduga bahwa tanaman marigold memiliki karakter yang kurang responsif terhadap pupuk NPK pada masa pertumbuhan vegetatif awal dari perlakuan konsentrasi maupun interval pemupukan NPK yang diberikan. Sesuai dengan pernyataan Hidayati (2009) yang menyatakan bahwa pertumbuhan vegetatif tanaman, yaitu tinggi tanaman dan diameter batang sangat responsif terhadap pupuk NPK. Begitu pula, karakter jumlah daun memiliki hubungan yang sinergis dengan tinggi tanaman, dimana konsentrasi NPK 150 $\mathrm{mg} /$ liter air dengan interval pemupukan 1 kali/minggu menunjukkan perlakuan terbaik.

Inisiasi bunga sangat berpengaruh terhadap tinggi rendahnya hormon giberelin, dimana semakin tinggi hormon ini maka frekuensi inisiasi bunga akan lebih tinggi. Subhan et.,al (2009) menyatakan bahwa pemberian pupuk NPK 15:15:15 dengan dosis 1 ton/ha memberi pengaruh terbaik terhadap tinggi tanaman, serapan hara, berat basah, berat kering, serta hasil tanaman tomat. Hal ini pun tejadi pada tanaman marigold yang memiliki respons positif terhadap aplikasi NPK.

Namun hal berbeda diutarakan Sumiati dan Sumarni (2006), bahwa inisiasi pembungaan distimulus oleh sintesis enzim giberelin alami sesuai dengan karakteristik tanaman itu sendiri, sehingga pemberian pupuk NPK tidak memiliki pengaruh terhadap tinggi rendahnya inisiasi pembungaan. Hal berbeda ditunjukkan pada parameter diameter bunga, ketersediaan unsur hara menjadi kunci terhadap besar kecilnya diameter bunga, sehingga semakin tinggi konsentrasi dan interval pemupukannya, maka diamter bunga menjadi semakin besar.

Oleh karena itu, kajian tentang aplikasi pupuk NPK berdasarkan konsentrasi atau dosis dengan interval waktu tertentu masih perlu dikaji lebih dalam untuk bisa mendapatkan informasi ilmiah yang tepat. Hasil dari penelitian ini minimal memberikan gambaran sementara takaran dari aplikasi NPK yang mendukung pertumbuhan marigold.

\section{KESIMPULAN}

Hasil penelitian menunjukkan bahwa perlakuan konsentrasi dan interval 
pemupukan NPK menunjukkan pengaruh yang nyata terhadap parameter vegetatif dan generatif tanaman, antara lain tinggi tanaman, jumlah daun, diameter batang, inisiasi bunga, diameter bunga, serta lama kesegaran bunga. Konsentrasi pupuk 150 $\mathrm{mg} /$ liter air dengan interval pemupukan NPK 1 kali/minggu menjadi rekomendasi yang dapat digunakan untuk meningkatkan kualitas tanaman marigold.

\section{UCAPAN TERIMAKASIH}

Penelitian ini merupakan kerjasama antara Balai Penelitian Tanaman Hias dengan Universitas Sultan Ageng Tirtayasa. Melalui penelitian ini dapat dihasilkan tulisan yang dapat memberikan informasi kepada para peneliti, akademisi, maupun dalam tingkat stake holder. Terimakasih diucapkan kepada para pihak yang membantu penelitian ini, khususnya staf pengajar Universitas Sultan Ageng Tirtayasa.

\section{DAFTAR PUSTAKA}

Andriolo, J. L., L. Erpen, F. L. Cardoso, C. Cocco, G. S. Casagrande, and D. I. Jänisch. 2011. Nitrogen Levels in The Cultivation of Strawberries in Soilless Culture. Horticultura Brasileira, 29(4): 516-519.

Ariana, M, A. Samie, M. A. Edriss and R. Jahanian. 2011. Effects of Powder and Extract Form of Green Tea and Marigold, and A-Tocopheryl Acetate on Performance, Egg Quality and Egg Yolk Cholesterol Levels of Laying
Hens in Late Phase Of Production. Journal of Medicinal Plant Research, 5(13): 2710-2716.

Bastari, T. 2006. Penerapan Anjuran Teknologi untuk Meningkatkan Efisiensi Penggunaan Pupuk. Pusat Penelitian Tanah dan Agriklomat. Badan Litbang Pertanian.Bogor.

Ebrahim, R., M. K. Souri, F. Ebrahimi and M. Ahmadizadeh. 2012. Growth and Yield of Strawberries Under Different Potassium Concentrations of Hydrophonic System in Three Substrates. World Applied Journal, 16(10): 1380-1386.

Hidayati N. 2009. Efektivitas Pupuk Hayati pada Berbagai Lama Simpan terhadap Pertumbuhan Tanaman Padi (Oryza sativa) dan Jagung (Zea mays). Repository Institut Pertanian Bogor.

Nath, TN. 2013. The Status of Micronutrients ( $\mathrm{Mn}, \mathrm{Fe}, \mathrm{Cu}, \mathrm{Zn})$ in Tea Plantations in Dibrugarh District of Assam, India. International Research Journal of Environment Sciences, 2(6): 25-30.

Puspita, T. A., K. Kushendarto, T. D. Andalasari, dan S. Widagdo. 2017. Pengaruh Pemberian Dosis Pupuk NPK Dan Pupuk Pelengkap Terhadap Pertumbuhan dan Produksi Tanaman Sedap Malam (Polianthes Tuberosa L.). Jurnal Agrotek Tropika, 5(1): 2026.

Subhan, N. Nurtika dan N. Gunadi 2009. Respon Tanaman Tomat terhadap Penggunaan Pupuk Majemuk NPK 15-15-15 pada Tanah Latosol pada Musim Kemarau. J.Hort., 16(1): 4048.

Sumiati, E. dan N. Sumarni. 2006. Pengaruh Kultivar dan Ukuran Umbi Bibit Bawang Bombay Introduksi Terhadap Pembungaan dan Produksi Benih. J.Hort., 16(1): 2-20.

Susilo, A., Suryanto, S. Sugiarto dan R. Maharani. 2010. Status Riset 
p-ISSN: 1410-0029; e-ISSN2549-6786

Agrin Vol. 23, No. 2, Oktober 2019

Reklamasi Bekas Tambang Batubara.

Pengembangan Kehutanan Balai

Samarinda: Badan Penelitian dan

Besar Penelitian Dipterokarpa. 